\title{
Partnership status and the human sex ratio at birth
}

\section{Karen Norberg}

\author{
National Bureau of Economic Research, 1050 Massachusetts Avenue, Cambridge, MA 02138, USA (norberg@nber.org)
}

\begin{abstract}
If two-parent care has different consequences for the reproductive success of sons and daughters, then natural selection may favour adjustment of the sex ratio at birth according to circumstances that forecast later family structure. In humans, this partnership-status hypothesis predicts fewer sons among extra-pair conceptions, but the rival 'attractiveness' hypothesis predicts more sons among extra-pair conceptions, and the 'fixed-phenotype' hypothesis predicts a constant probability of having a son, regardless of partnership status. In a sample of 86436 human births pooled from five US population-based surveys, I found $51.5 \%$ male births reported by respondents who were living with a spouse or partner before the child's conception or birth, and $49.9 \%$ male births reported by respondents who were not $\left(\chi^{2}=16.77\right.$, d.f. $\left.=1, p<0.0001\right)$. The effect was not explained by paternal bias against daughters, by parental age, education, income, ethnicity or by year of observation, and was larger when comparisons were made between siblings. To my knowledge, this is the first direct evidence for conditional adjustment of the sex ratio at birth in humans, and could explain the recent decline in the sex ratio at birth in some developed countries.
\end{abstract}

Keywords: sex ratio; mating system; human; evolution

\section{INTRODUCTION}

Sex-allocation theory predicts that parents may vary the sex of their offspring according to conditions that have different fitness outcomes for sons and daughters (Hamilton 1967; Charnov 1982). Most sex-allocation models are inhabited by male partners who go their own way once the offspring has been conceived, but modern human reproduction features high levels of paternal investment; if two-parent care has different consequences for the inclusive fitness of sons and daughters, then natural selection could favour a parental ability to vary the sex of offspring according to signals that forecast later paternal investment or family constellation. In the present study, I call this the 'partnership status hypothesis'. Evidence supporting their hypothesis has been reported for several species of birds: studies have found a lower proportion of sons among the offspring of mothers with secondary-mate status in house wrens, great reed warblers, oriental reed warblers and yellow-headed blackbirds (Patterson et al. 1980; Nishiumi 1998; Westerdahl et al. 2000; Albrecht et al. 2002; reviewed in Hasselquist \& Kempenaers 2002), and one study has found a lower proportion of sons among females who have changed mates, compared with females who remain with the same male (Oddie \& Reim 2002). In humans, there were many nineteenth century reports of a lower percentage of boys among human births occurring outside marriage (Darwin 1874), and studies in modern Kenya have found a lower percentage of sons among polygynously married women (Whiting 1993). Furthermore, there has been a small, previously unexplained decline in the sex ratio at birth in the USA, Canada and Great Britain (Marcus et al. 1998), over a period of time that has also been marked by a rise in single-parent births (CDC 2000). In the present study, I compare the partnership-status hypothesis with four competing hypotheses. These are 'attractiveness' hypothesis, reverse causality, the 'fixed phenotype' hypothesis, and the maternal-resource-status or 'narrow-sense Trivers-Willard' hypotheses. I find that parents who were living with a spouse or opposite-sex partner before a child's conception were $c a .14 \%$ more likely to have a male child than when they were not; where the competing hypotheses make contrasting predictions, the results favour an adaptive partnership-status effect.

The plausibility of the partnership-status hypothesis in humans depends, first, on whether the partnership status at the time of sex-ratio adjustment is likely to have been associated with later family environment in ancestral human populations. High levels of paternal involvement may have been an early innovation in the hominid line (Marlowe 2000; Larsen 2003). Cohabitation is widely used as a sign of pair-bond status across cultures and species; although it has a different significance in uniparental, monogamous, polygynous and extended-family mating and breeding systems, it is plausible that males who share a shelter with a female partner usually make larger net parental investments than who do not. There are at least two possible reasons: (i) because cohabitation increases paternity confidence by reducing the costs of mate guarding at the time of conception, and (ii) because cohabitation reduces the costs of cooperative childrearing.

The plausibility of an adaptive partnership-status effect also depends on whether family structure has had different fitness consequences for sons and daughters. Although the truth of this claim is controversial, there are several reasons why it could be so. First, is the possibility that family constellation could have larger effects on the fitness of sons because the variance in male reproductive success is larger than the variance in female reproductive success. This is the 'broad sense' Trivers-Willard hypothesis, but as Trivers and Willard point out in their original paper, the predicted relationship between parental resource status and offspring resource status becomes complicated when parental investments are the result of bargaining between two or more parents (Trivers \& Willard 1973; also Becker 1974). Second, is the possibility that differences in fitness could arise from sex-specific dispersal or role specializa- 
tion, leading to sex differences in the offspring's opportunity for sex-role learning or parental repayment in different family constellations (Clark 1978; Lamb 1996; Seielstad 1998; Emlen et al. 1986). Last, is the possibility that sex-ratio effects could be due to conflicts of interest between the male and female partner: if male offspring are more costly to rear, then females could respond to the prospects of partner defection by reducing the likelihood of a male birth (Cockburn et al. 2002).

The best-known sex allocation model in relation to pairbond status is the attractiveness hypothesis, which makes a prediction about extra-pair conceptions that directly contrasts with the partnership-status hypothesis: if females make trade-offs between signs forecasting 'good genes' and 'good parenting' in a potential mate, and if sons are more likely to benefit from inheriting a father's attractiveness, then the fathers of extra-pair conceptions are likely to be particularly attractive, and the attractiveness hypothesis predicts that offspring of extra-pair conceptions should tend to be sons (Burley 1981; Ellegren et al. 1996; Kempenaers et al. 1997).

In addition to the attractiveness hypothesis, there are three other hypotheses that can be tested in the present study. First, is the question of direction of causality: several recent studies have suggested that child sex might influence the stability of the parents' marriage (e.g. Edlund 1999; Lundberg \& Rose 2003). To distinguish an effect of partnership status on child sex from an effect of child sex on the parents' later partnership status, I construct measures of the parent's partnership status before the child's sex could have been known to the parents; in three out of the five samples, I am able to use household composition recorded by an interviewer before the child's conception.

Second, it is possible that partnership-status effects could be due to heritable or environmentally determined but fixed parental phenotypes that are correlated with partnership status and offspring sex. Sex-allocation theory predicts that such propensities could be maintained by frequency-dependent selection, and different frequencies could be maintained in different populations of origin. For example, in the USA, African-American parents have slightly fewer male births than parents of European origin, and this has been attributed to heritable differences in hormonal status biasing offspring sex (James 1987). Environmental factors such as endocrine disruptors have also been proposed as an explanation for the decline in the sex ratio at birth in certain countries (reviewed in Marcus et al. 1998). We can distinguish the conditional model from heritable or environmentally determined phenotypes that remain relatively constant between births, by making comparisons among siblings. The signature of conditional sex-ratio adjustment is that the same parent will have offspring of different sexes under different conditions, but a fixed phenotype will reveal no association between partnership and offspring sex when the comparisons are made between siblings who share the parent with that trait. Furthermore, because our sample includes both full and half-siblings, some sharing the same mother and some the same father, we can detect fixed phenotypes that may be expressed only in the parent of a single sex (e.g. Haig 1997), by comparing estimates when siblings are grouped by father or by mother.
Third, is the possibility that a partnership-status effect is due to confounding exposures that vary with partnership status in a modern US population. If a partnership-status effect were actually due to family resource status (Trivers \& Willard 1973) parental age or child birth order (James 1987), or to modern exposures that vary with time (e.g. Marcus et al. 1998), then the variance attributed to partnership status should be reduced when more direct measures are included in a multiple regression model.

\section{DATA AND MEASURES}

This study uses a sample of live births pooled from four publicly available prospective surveys, and one retrospective survey: the 1959 National Collaborative Perinatal Project (NCPP; National Institute of Neurological and Communicative Diseases \& Stroke 1985), the 1968 Panel Study of Income Dynamics (PSID; Hill 1991), the 1969 National Longitudinal Survey of Young Women (NLSYW) and the 1979 National Longitudinal Survey of Youth (NLSY; US Bureau of Labor Statistics 2001), and the 1995 National Survey of Family Growth (NSFG; US Department of Health and Human Services 1997). Together, these five studies yield a sample of 86436 children born to 61044 US families between 1959 and 1998. Qualitatively similar results are obtained in each of the five individual samples, but not all of the results are statistically significant; the pooled sample is large enough to detect these relatively small effects. The four most recent studies provide information about the responding parent's household composition before the child's conception, and the earliest study (the NCPP) provides information about household composition at the time of registration for prenatal care. All five studies include some families with multiple siblings in the sample; there were 17724 families with two or more sampled siblings, and out of these, 2857 families had sets of children of mixed sexes and mixed exposure to parental household types at the time of conception. The inclusion of both male and female respondents in the NLSY allows us to test for mother-specific versus father-specific effects; and the 40 year span of observation allows some evaluation of time trends, including comparisons before and after the legalization of abortion in the USA.

Respondents in all five surveys could be classified into three mutually exclusive household types: (i) responding parent married, with spouse present in the household; (ii) responding parent unmarried, with an opposite sex unrelated adult living in the household; and (iii) other. In each sample, we observe the respondent's relationship status before the parent could have become aware of the child's sex, and in four out of the five studies, we observe households before the child's conception. However, the timing of this 'index' observation differed across the five samples. In the NCPP, mother's partnership status was recorded at the first prenatal visit; in the PSID, NLSYW and NLSY, the responding parent's household composition was recorded at the most recent interview 10 months or more before the child's birth; and in the NSFG, the measure reflects the mother's household composition in the month before the child's conception. Although household type was the predictor of primary interest, birth order, year of birth, parental age, ethnicity and education were selected 
as further control variables because they were available in all five surveys, and have been associated with the probability of marriage or cohabitation, and with offspring sex, in other human studies (James 1987). In the NSFG, mother's income and education were observed in a single year (1993); in the other surveys, all parental characteristics were recorded at the index observation before the child's birth. The responding parent's education was the only measure of socio-economic status available in the same form in all five surveys, but family income, per capita income and the ratio of the family's income to the official US federal poverty threshold were available in one or more individual studies. All income measures were standardized to 1982 dollars using the consumer price index of the US Bureau of Labor Statistics (US Council of Economic Advisors 2003).

The measures used in the present study are similar across the five surveys, but there are differences in sample selection and study design. The latter four surveys are statistically representative of specific cohorts of the US population, and yield information about the parent's household status before the child's conception. The NCPP is based on a convenience sample of mothers giving birth at participating hospitals, and first collects information when the mother registers for prenatal care. Both the NLSY and the PSID include births reported by male sample members; because of potential bias in the following rules used by the PSID, the offspring of male PSID sample members were dropped from this study, but this choice did not affect the overall results. The 1995 NSFG is a retrospective survey; births were selected for the present study if they occurred between 1991 and 1995, the years for which the most detailed information was collected. Children from all five surveys were included if there was information about the child's sex, birth order and year of birth, and about the responding parent's marital status, household type, ethnicity, age and education at the index observation. The annual retention rates for the four longitudinal surveys range from $95.9 \%$ to $98.5 \%$.

\section{STATISTICAL METHODS}

Statistical analyses were performed using the Stata software package (Stata Corporation 2003). In the bivariate analyses, the associations between the independent variables and offspring sex are evaluated in contingency tables, using $\chi^{2}$ tests to evaluate the hypothesis that sons and daughters are randomly distributed across categories, and the common adds ratio and $\chi^{2}$ tests across studies are estimated using the Mantel-Haenszel test (Blettner et al. 1999). Because of differences in study design sampling weights are not used, but inclusion of weights does not substantially alter any of the reported results. In the multiple effect analyses, I use ordinary and conditional logistic regression models to control for observable and unobservable factors that may confound an association between partnership status and child sex. Logistic regression is a form of generalized linear modelling, using a logit-link function for the dichotomous outcome variable, and assuming a binomial error distribution. For a discussion of statistical analysis of sex ratios, see Wilson \& Hardy (2002).
The logistic regression models can be expressed as: $\ln [p /(1-p)]=b_{0}+b_{1} x_{1}+b_{2} x_{2}+b_{3} x_{3}+\ldots+b_{k} x_{k}$,

where $p$ is the probability of a child being male, and $x_{1} \cdots x_{k}$ represent variables measuring parental partnership status, child's birth year, child's birth order with the responding parent, and the responding parent's age, highest grade completed, black and Hispanic ethnicity, dummy variables indicating study sample, and in some models, poverty status or family income. I use 'robust' standard errors to correct for possible correlations among siblings.

Sibling comparisons make it possible to contrast the partnership-status hypothesis with 'fixed-phenotype' models by controlling for exposures that do not differ between siblings who share the observed parent. For the sibling comparisons, I use conditional logistic models with births stratified by the responding parent. The conditional or fixed-effect logistic regression models are given by:

$\ln [p /(1-p)]=b_{1 i j} x_{1 i j}+b_{2 i j} x_{2 i j}+b_{3 i j} x_{3 i j}+\cdots+b_{k i j} x_{k i j}$,

where $x_{1 i j} \cdots x_{k i j}$ represent family attributes that can change from one sibling to the next, observed for the $j$ th sibling in the $i$ th family. In these models, we wish to estimate the association between the independent variables and offspring sex within families; the model assumes different intercepts for each family, but these are treated as nuisance variables, and are not calculated-they are 'conditioned out' of the analysis. The coefficient for household status is therefore interpretable as the log of the ratio of the odds of a child being male if the parent was married or living with a partner at the index observation, relative to the odds of a sibling being male if the same parent was not living with a partner at the sibling's index observation. In some of these models, I estimate separate household status effects for male and female parents, or for black and other parents.

\section{RESULTS}

Table 1 describes the five samples. Overall, despite differences in decade, social context, sampling strategies, study design, respondent sex and fraction of parents in each household type, there were consistently fewer boys in each sample among children whose parents were living apart, than among children whose (presumed) parents were living together at the time of the index observation. In the pooled sample, there were $51.4 \%$ boys among children whose parents were married and living together, $52.2 \%$ boys among children whose parents were unmarried but living together, but only $49.9 \%$ boys among children whose parents were living apart; the contrast between single parents and all others was highly significant $\left(\chi^{2}=16.77\right.$, d.f. $=1, p<0.0001$ ), but the contrast between those who were married and living together with those who were unmarried but living together was not significant $\left(\chi^{2}=1.62\right.$, d.f. $\left.=1, p=0.20\right)$. Married and unmarried cohabiting households were therefore combined for the rest of the analyses reported here. The last row of table 1 shows that each of the five samples yielded a positive point estimate for the odds ratio of male to female births in shared and non-shared households. These estimates range from 1.048 to 1.195 , with a pooled estimate of $1.066(95 \%$ confidence interval 1.034-1.098, $p<0.0001)$; in three out of the five samples the estimates were separately significant 


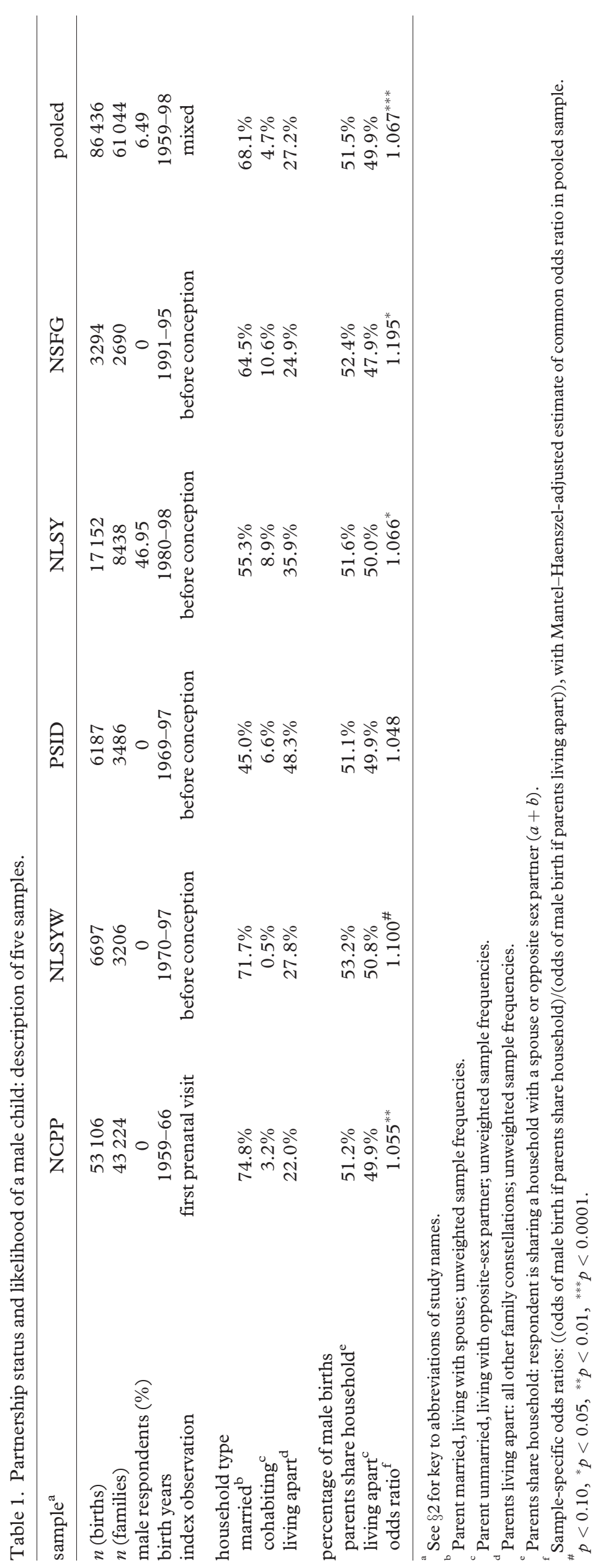


at the 0.05 level. The strongest contrast was observed in the NSFG, and the weakest contrast was observed in the PSID, but a Breslow-Day test indicates no significant difference in the odds ratio of this contrast across studies, $\left(\chi^{2}=2.67\right.$, d.f. $\left.=4, p=0.61\right)$, thus justifying the use of a pooled sample (Blettner et al. 1999).

The results of multiple logistic-regression analyses were nearly identical to the results of these simple cross tabulations. In separate comparisons between the independent variables and offspring sex, parents with more years of education, members of the NLSYW sample and parents who were living with an opposite sex partner at the index observation were more likely to have a son, and AfricanAmerican parents were less likely to have a son, than other parents. However, when these independent variables were compared in multiple logistic-regression models, the coefficients for race, study sample and years of education were reduced in absolute magnitude by $25-40 \%$; although one measure-African-American ethnicity-remained statistically significant in some models, only partnership status remained statistically significant in all models tested. In the full sample, children whose parents were living together at the index observation were $5.4 \%$ more likely to be male than children whose parents were living apart (odds ratio of $1.054 ; 95 \%$ confidence interval of 1.019-1.089, $p=0.002$ ); this estimate was slightly larger (odds ratio $1.076,95 \%$ confidence interval $1.021-1.134, p=0.006$ ), when the pooled sample was restricted to the surveys observing households before conception. Other model specifications, including the use of categorical indicators of education, birth year, and birth order, interaction terms, alternate measures of income, and inclusion or exclusion of individual covariates, yielded no other significant associations, and no change in the association between partnership status and child sex.

Table 2 shows the results of within-family conditional logistic regressions comparing siblings who share a responding parent. The point estimates are larger than those from the ordinary logistic models, although the confidence intervals overlap. In model 1 , the odds of a male birth among children whose parents were married or cohabiting at the index observation were $13.8 \%$ higher than the odds among siblings whose parents were living apart (odds ratio $1.138,95 \%$ confidence interval 1.052-1.230, $p=0.001)$. The estimate is almost identical in model 2, which is restricted to the sample of parents observed before the child's conception (odds ratio 1.136, 95\% confidence interval 1.036-1.247, $p=0.007$ ). In model 3, separate estimates for male and female respondents were similar, and both was statistically significant; and in model 4, separate estimates for black and other respondents were also similar, and statistically significant. Interaction terms in all models were non-significant; inclusion or exclusion of covariates and categorical indicators for age, year and education did not change the results, and between models 5 and 6 there was no significant change in the estimate when the model included additional information about family income.

\section{DISCUSSION}

These results provide support for the partnership-status hypothesis compared with four competing alternatives- the attractiveness hypothesis, the fixed-phenotype hypothesis, reverse causality, and confounding by family income, race, parental age or birth order - which might explain an association between partnership status and offspring sex. In the pooled sample of 86436 births I find $51.5 \%$ male births reported by respondents who were living with an opposite sex partner at the 'index' observation, and $49.9 \%$ male births reported by respondents who were not $\left(\chi^{2}=15.77\right.$, d.f. $\left.=1, p<0.0001\right)$. When the comparisons were made among siblings, children who were conceived when the responding parent was living with an opposite-sex partner were ca. $14 \%$ more likely to be boys than siblings conceived when the parents were living apart, with $p<0.007$. This association was present across all five samples, and across varied specifications, including multiple-regression analyses controlling for parental ethnicity, age, education, or family income, and child's birth order or year of birth, and conditional logistic regressions controlling for both maternal and paternal 'fixed effects'. These results therefore lead to rejection of the 'attractiveness' hypothesis, which predicts that the offspring of extra-pair or non-partnership conceptions would be more likely to be male, and the 'fixed phenotype' hypothesis, which predicts that parents may have a fixed propensity to have more or fewer male or female offspring. Furthermore, in multipleregression analyses, the partnership-status effect was not explained by maternal education or family resource status, and appeared to explain ca. 25-40\% of the (small) associations between child sex and parental age, race or parity, and child's year of birth.

Because partnership status was observed before conception, the association is unlikely to be due to an effect of child sex on the parents' partnership status, though certain kinds of selection bias cannot be ruled out. For example, selective attrition could explain the present results if single mothers pregnant with sons were more likely to drop out of the surveys than single mothers pregnant with daughters. Annual response rates better than 95\%, a lack of prior evidence that child sex affects survey attrition, and the similarity of results over a 40 year period marked by a rapid decline in social stigma against single-parent birth, argue against this interpretation. It would be surprising to find much intentionally sex-selective abortion in the United States, but unintentionally sex-selective abortion could explain the present results if the out-of-partnership pregnancies at risk for abortion were, for unknown biological reasons, more likely to be male. However, there was no statistically significant difference between the effect estimate from the NCPP, a decade before legalization of abortion in the United States, and estimates from the four more recent samples.

There are several proximal mechanisms by which birds and mammals could bias the sex of their offspring in relation to pair-bond status (Krackow 1995). For example, parental hormone status and the frequency and timing of intercourse in relation to ovulation have been associated with offspring sex (James 1987; Grant 1998), and couples that are living together probably have more opportunity for sexual intercourse than couples that are living apart. Duration of partnership could also influence the risk of sex-selective miscarriage through effects on maternal tolerance of foetal antigens (Klonoff-Cohen et al. 1989; Robillard et al. 1994), although it has been argued that 


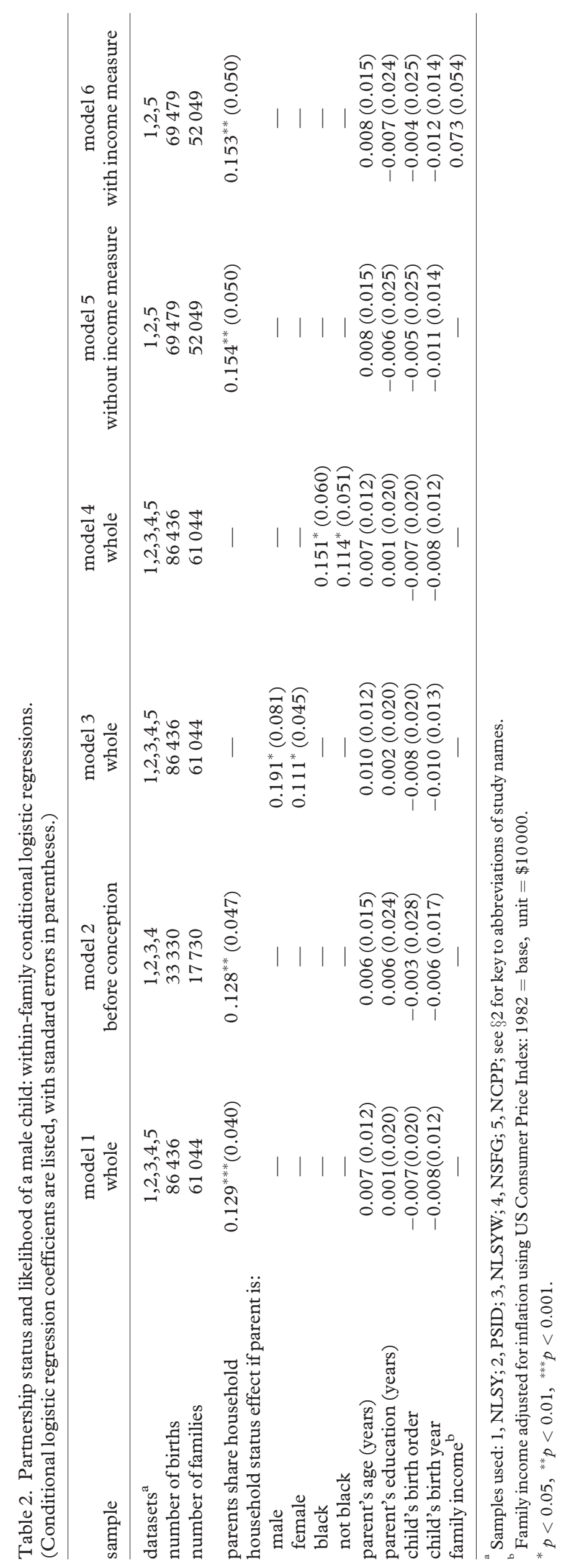


selective miscarriage is a costly method of sex-ratio control that may rarely be favoured by natural selection (Krackow 2002).

Other modern exposures correlated with partnership status might explain the present results, but such exposures would need to be closely tied to reproductive behaviour. Hormonal methods of contraception, introduced to the USA in 1960, could influence the sex ratio through mate choice and thus risk of miscarriage, and barrier methods of contraception, in use throughout the twentieth century, could increase the risk of sex-selective miscarriage by interfering with the development of maternal tolerance of paternal antigens (Shiono et al. 1982; Robillard et al. 1994; Wedekind et al. 1995).

Although such alternative explanations remain to be investigated, the present study provides the strongest evidence, so far, for conditional sex allocation in humans. The results are most consistent with an adaptive partnershipstatus hypothesis, and are least consistent with the predictions of the attractiveness and fixed phenotype hypotheses in this population.

This study was made possible by resources and technical support provided by the NBER. The author thanks Don Cox, Dan Feenberg, Peter Gray, Ronald Lee, Frank Marlowe, Steven Orzack, Stephan Pischke, Richard Sosis, Bill Stubblefield and an anonymous reviewer for many comments. Earlier versions of this paper were presented to the Human Behavior and Evolution Society in June 2001, the labour economics seminar of Harvard University in November 2002, the NBER Child Program, April 2003, and the annual meeting of the Population Association of America in May 2003.

\section{REFERENCES}

Albrecht, D. J. \& Johnson, L. S. 2002 Manipulation of offspring sex ratio by second-mated female house wrens. Proc. R. Soc. Lond. B 269, 461-465. (doi:10.1098/rspb.2001. 1914)

Becker, G. S. 1974 A theory of marriage: part II. F. Polit. Econ. 82, s11-s26.

Blettner, M., Sauerbrei, W., Schlehofer, B., Scheuchenpflug, T. \& Freidenreich, C. 1999 Traditional reviews, metaanalyses and pooled analyses in epidemiology. Int. F. Epidemol. 28, 1-9.

Burley, N. 1981 Sex ratio manipulation and selection for attractiveness. Science 211, 721-722.

CDC 2000 Nonmarital childbearing in the United States, 1940-1999. National Vital Statist. Rep. 48, 1-39.

Charnov, E. L. 1982 The theory of sex allocation. Princeton, NJ: Princeton University Press.

Clark, A. B. 1978 Sex ratio and local resource competition in a prosimian primate. Science 201, 163-165.

Clutton-Brock, T. 1982 Sons and daughters. Nature 298, 11-13.

Cockburn, A., Legge, S. \& Double, M. C. 2002 Sex ratios in birds and mammals: can the hypotheses be disentangled? In Sex ratios: concepts and research methods (ed. I. Hardy), pp. 266-286. Cambridge University Press.

Darwin, C. 1874 The descent of man, 2nd edn. New York: Random House.

Edlund, L. 1999 Son preference, sex ratios, and marriage patterns. F. Polit. Econ. 107, 1275-1304.

Ellegren, H., Gustafsson, L. \& Sheldon, B. C. 1996 Sex ratio adjustment in relation to paternal attractiveness in a wild bird population. Proc. Natl Acad. Sci. USA 93, $11723-11728$.
Emlen, S. T., Emlen, J. M. \& Levin, S. A. 1986 Sex-ratio selection in species with helpers-at-the-nest. Am. Nat. 127, $1-8$.

Grant, V. J. 1998 Personality, evolution and the sex ratio. London: Routledge.

Haig, D. 1997 Parental antagonism, relatedness asymmetries, and genomic imprinting. Proc. R. Soc. Lond. B 264, 16571662. (doi:10.1098/rspb.1997.0230)

Hamilton, W. D. 1967 Extraordinary sex ratios. A sex-ratio theory for sex linkage and inbreeding has new implications in cytogenetics and entomology. Science 156, 477-488.

Hasselquist, D. \& Kempenaers, B. 2002 Parental care and adaptive brood sex ratio manipulation in birds. Phil. Trans. R. Soc. Lond. B 357, 363-372. (doi:10.1098/rstb.2001. 0924)

Hill, M. S. 1991 The panel study of income dynamics: a user's guide. London: Sage.

James, W. H. 1987 The human sex ratio, part 1. A review of the literature. Hum. Biol. 59, 721-752.

Kempenaers, B., Verheyren, G. R. \& Dhondt, A. A. 1997 Extrapair paternity in the blue tit (Parus caeruleus): female choice, male characteristics, and offspring quality. Behav. Ecol. 8, 481-492.

Klonoff-Cohen, H. S., Savitz, D. A., Cefalo, R. C. \& McCann, M. F. 1989 An epidemiological study of contraception and preeclampsia. F. Am. Med. Assoc. 262, 31433147.

Krackow, S. 1995 Potential mechanisms for the sex ratio adjustment in mammals and birds. Biol. Rev. 70, 225-241.

Krackow, S. 2002 Why parental sex ratio manipulation is rare in higher vertebrates (invited article). Ethology 108, 10411056.

Lamb, M. E. 1996 The development of father-infant relationships. In The role of the father in child development, 3rd edn. (ed. M. Lamb), pp. 104-120. New York: Wiley.

Larsen, C. S. 2003 Equality for the sexes in human evolution? Early hominid sexual dimorphism and implications for mating systems and social behavior. Proc. Natl. Acad. Sci. USA 100, 9103-9104.

Lundberg, S. \& Rose, E. 2003 Child gender and the transition to marriage. Demography 40, 333-349.

Marcus, M., Kiely, J., Xu, F., McGeehin, M., Jackson, R. \& Sinks, T. 1998 Changing sex ratio in the United States 1969-1995. Fert. Steril. 70, 270-273.

Marlowe, F. 2000 Paternal investment and the human mating system. Behav. Process. 51, 45-61.

National Institute of Neurological and Communicative Diseases and Stroke 1985 Collaborative perinatal project documentation. Washington: National Archives and Records Administration. Also available at http://www.nber.org/docs/ $\mathrm{cpp} /$.

Nishiumi, I. 1998 Brood sex ratio is dependent on female mating status in polygynous great reed warblers. Behav Ecol. Sociobiol. 44, 9-14.

Oddie, K. R. \& Reim, C. 2002 Egg sex ratio and paternal traits using within-individual comparisons. Behav. Ecol. 13, 503510.

Patterson, C. B., Erckman, W. J. \& Orians, G. H. 1980 An experimental study of parental investment and polygyny in male blackbirds. Am. Nat. 116, 757-769.

Robillard, P. Y., Hulsey, T. C., Perianin, J., Janky, E., Miri, E. H. \& Papiernik, E. 1994 Association of pregnancyinduced hypertension with duration of sexual cohabitation before conception. Lancet 344, 973-975.

Seielstad, M. T., Minch, E. \& Cavalli-Sforza, L. L. 1998 Genetic evidence for a higher female migration rate in humans. Nature Genet. 20, 278-280. 
Shiono, P. H., Harlap, S. \& Ramcharan, S. 1982 Sex of offspring of women using oral contraceptives, rhythm and other methods of birth control around the time of conception. Fert. Steril. 37, 367-372.

Stata Corporation 2003 Stata base reference manual, release 8. College Station, TX: Stata Corporation.

Trivers, R. L. \& Willard, D. E. 1973 Natural selection of parental ability to vary the sex ratio of offspring. Science $\mathbf{1 7 9}$, 90-92.

US Bureau of Labor Statistics 2001 NLS handbook, 2000. Washington, DC: US Government Printing Office.

US Council of Economic Advisors 2003 Economic report of the President. Washington, DC: US Government Printing Office.

US Department of Health and Human Services 1997 Public use data file documentation, national survey of family growth, cycle 5: 1995 user's guide. Hyattsville, MD: NCHS.
Wedekind, C., Seebeck, T., Bettens, F. \& Paepke, A. J. 1995 MHC-dependent mate preference in humans. Proc. R. Soc. Lond. B 260, 245-249.

Westerdahl, H., Bensch, S., Hansson, B., Hasselquist, D. \& von Schantz, T. 2000 Brood sex ratios, female harem status and resources for nestling provisioning in the great reed warbler (Acrocephalus arundinaceus). Behav. Ecol. Sociobiol. 47, 312-318. Whiting, J. 1993 The effects of polygyny on sex ratio at birth. Am. Anthropol. 95, 435-442.

Wilson, K. \& Hardy, I. 2002 Statistical analysis of sex ratios: an introduction. In Sex ratios: concepts and research methods (ed. I. Hardy), pp. 63-72. Cambridge University Press.

As this paper exceeds the maximum length normally permitted, the authors have agreed to contribute to production costs. 